\title{
DNA binding and oxidative DNA damage induced by climacostol-copper(II) complexes: Implications for anticancer properties
}

\author{
Luana Quassinti ${ }^{a}$, Francesco Ortenzi ${ }^{a}$, Enrico Marcantoni ${ }^{\mathrm{b}}$, Massimo Ricciutelli ${ }^{\mathrm{c}}$, Giulio Lupidi $^{\mathrm{d}}$, \\ Claudio Ortenzi ${ }^{\mathrm{e}}$, Federico Buonanno ${ }^{\mathrm{e}}$, Massimo Bramucci ${ }^{\mathrm{a}, *}$ \\ a School of Pharmacy, Section of Physiology, University of Camerino, Via Gentile III da Varano, 62032 Camerino, Italy \\ ${ }^{\mathrm{b}}$ School of Sciences and Technologies, Section of Chemistry, University of Camerino, Via S. Agostino 1, 62032 Camerino (MC), Italy \\ ${ }^{\mathrm{c}}$ Laboratory of HPLC-MS, University of Camerino, Via S. Agostino 1, 62032 Camerino (MC), Italy \\ ${ }^{\mathrm{d}}$ School of Pharmacy, Section of Biochemistry, University of Camerino, Via Gentile III da Varano, 62032 Camerino, Italy \\ ${ }^{\mathrm{e}}$ Laboratory of Protistology and Biology Education, University of Macerata, P. le Bertelli 1, 62100 Macerata, Italy
}

\section{A R T I C L E I N F O}

\section{Article history:}

Received 10 April 2013

Received in revised form 4 August 2013

Accepted 16 August 2013

Available online 28 August 2013

\section{Keywords:}

Climacostol

DNA damage

Copper

Reactive oxygen species

\begin{abstract}
A B S T R A C T
Climacostol is a natural toxin isolated from the freshwater ciliated protozoan Climacostomum virens and belongs to the group of resorcinolic lipids. Climacostol exerts a potent antimicrobial activity against a panel of bacterial and fungal pathogens. In addition it inhibits the growth of tumor cell lines in a dose-dependent manner by inducing programmed cell death via intrinsic pathway. In this work, we investigated the possibility that climacostol exerts a prooxidant effect, inducing plasmid DNA strand breakage and eukaryotic DNA damage in presence of $\mathrm{Cu}(\mathrm{II})$ ions. Inhibition of DNA breakage using SOD, catalase and neocuproine confirmed the involvement of reactive oxygen species and $\mathrm{Cu}(\mathrm{I})$ ions in the DNA damage. UV-visible absorption changes and mass spectrometric analysis identified a product of reaction as a deprotonated form of climacostol. Study of the interaction with DNA, using fluorescence spectroscopic techniques, showed that climacostol binds with DNA. Given the structure-activity relationship of this compound and the mechanism of its prooxidant effect, we propose that the $\mathrm{Cu}(\mathrm{II})$-mediated oxidative DNA damage by climacostol could explain its antimicrobial and antiproliferative activity.
\end{abstract}

(c) 2013 Elsevier Ireland Ltd. All rights reserved.

\section{Introduction}

Climacostol (1,3-dihydroxy-5-[(Z)-non-2'-enyl]benzene) is a toxin physiologically produced by the ciliated protozoan Climacostomum virens for chemical defense against unicellular and multicellular predators [1-3]. From a chemical point of view, the toxin belongs to the family of resorcinolic lipids (also called alkylresorcinols, or 5-alkylresorcinols), widely detected in prokaryotes as well as in single-celled and multicellular eukaryotes [4,5]. To date, climacostol has been chemically synthesized by three alternative pathways [6-9]. In the approach adopted by Fiorini et al. [9] and used in this study, climacostol was obtained as a substantially pure compound, avoiding contamination with the undesired $(E)$-isomer present in the natural toxin purified from cultures of $C$. virens.

The compounds of this group have attracted attention for potential use in therapy and/or prevention of specific classes of diseases [10-13] because of their antimicrobial, cytotoxic, anticancer and genotoxic activities. Recent studies performed to evaluate the

\footnotetext{
* Corresponding author. Tel.: +39 0737403262; fax: +39 0737403290.

E-mail address: massimo.bramucci@unicam.it (M. Bramucci).
}

effects of climacostol on bacteria, fungi, protozoa, human cancer cell lines, and isolated rat mitochondria have suggested that the protozoan toxin exhibits this spectrum of activities, and have indicated some peculiar structural and functional traits of the molecule. Petrelli et al. [14] have reported that climacostol can exert a potent antimicrobial activity against a panel of bacterial and fungal pathogens, including Staphylococcus, Streptococcus, Enterococcus, and Candida. Buonanno and Ortenzi [15] demonstrated that the cytotoxic potency of climacostol on free-living freshwater ciliates can be modulated by the substitution of the double bond in the aliphatic chain of the toxin with a single or a triple one. Muto et al. $[16,17]$ found that climacostol specifically inhibits respiratory chain complex I in rat liver mitochondria, inducing a consequent generation of reactive oxygen species (ROS). Finally, Buonanno et al. [18] and Fiorini et al. [9] observed that climacostol can inhibit the growth of human cancer cell lines in a dose-dependent manner and induce apoptosis by triggering the mitochondrial (intrinsic) pathway.

The intrinsic pathway is the most common one for apoptosis in vertebrates and can be activated by a variety of cellular stressors, including ROS and DNA-damaging molecules. Of note are reports 
that some resorcinolic lipids are capable of interacting with the DNA double helix; they are incorporated into the helix interior by intercalation of chains $[5,19]$. Furthermore, it was observed that some members of the class of resorcinolic lipids possess the ability to induce $\mathrm{Cu}^{2+}$-dependent DNA cleavage $[20,21]$ associated with ROS formation and apoptosis induction [22-25].

On the basis of these considerations, the objective of this study was to assess the prooxidant activity of climacostol. The results demonstrate that climacostol causes the copper-dependent strand breaks of pBR322 plasmid DNA, indicating that this alkylresorcinol exerts a prooxidant effect. Our examination of the structureactivity relationship of this compound and the mechanism of its prooxidant effect enables us to propose that the $\mathrm{Cu}(\mathrm{II})$-mediated oxidative DNA damage by climacostol could explain its antimicrobial and antiproliferative activity.

\section{Materials and methods}

\subsection{Materials}

Chemically synthesized climacostol was obtained as previously reported [9]. Supercoiled plasmid pBR322 DNA, calf thymus DNA (ct-DNA), catalase, neocuproine, ethidium bromide (EB), diethylenetriaminepentaacetic acid (DTPA) and agarose were purchased from Sigma-Aldrich (St. Louis, MO, USA). All other chemicals were of analytical grade.

\subsection{Assay for oxidative DNA strand breakage}

The induction of DNA strand breakage by climacostol was assessed by using agarose gel electrophoresis to measure the conversion of the supercoiled pBR322 plasmid DNA to open circular and linear forms [26]. pBR322 DNA $(0.180 \mu \mathrm{g})$ was incubated with the indicated concentration of climacostol and/or $\mathrm{Cu}$ (II) in phosphate buffer saline (PBS) at $\mathrm{pH} 7.4$ and $37{ }^{\circ} \mathrm{C}$ for $60 \mathrm{~min}$. After incubation, the samples were mixed with $2 \mu \mathrm{l}$ of a solution containing $50 \%$ glycerol $(\mathrm{v} / \mathrm{v}), 40 \mathrm{mM}$ EDTA and $0.05 \%$ bromophenol blue to stop the reaction, and the reaction mixture was immediately subjected to $1 \%$ agarose gel stained with ethidium bromide. The samples were electrophoresed in a horizontal slab gel apparatus in TBE buffer containing $40 \mathrm{mM}$ Tris- $\mathrm{HCl}, 89 \mathrm{mM}$ boric acid and $2 \mathrm{mM}$ EDTA, pH 8.0, at $5 \mathrm{~V} / \mathrm{cm}$ for $3 \mathrm{~h}$. The gel was photographed using a UV transilluminator.

\subsection{Detection of $\mathrm{Cu}(\mathrm{II})$ reduction}

Copper reduction was tracked by determining the cuprous ion concentration with neocuproine [27]. The $1 \mathrm{ml}$ samples contained PBS buffer, $500 \mu \mathrm{M}$ of neocuproine, $50 \mu \mathrm{M} \mathrm{CuCl}_{2}$, and various concentrations of climacostol. The neocuproine- $\mathrm{Cu}(\mathrm{I})$ complex was determined by measuring the absorbance at $450 \mathrm{~nm}$ immediately after mixing the reagents.

\subsection{Detection of superoxide anion radical generation}

The amount of $\mathrm{O}_{2}^{--}$generation was determined by measurement of cytochrome c reduction. A mixture containing $40 \mu \mathrm{M}$ ferricytochrome c, $100 \mu \mathrm{M}$ climacostol, $20 \mu \mathrm{M} \mathrm{CuCl}_{2}$ and $2.5 \mu \mathrm{M}$ DTPA in $1.5 \mathrm{ml}$ of $10 \mathrm{mM}$ sodium phosphate buffer ( $\mathrm{pH} 7.8$ ) was incubated at $37^{\circ} \mathrm{C}$. A maximum absorption at $550 \mathrm{~nm}$ due to ferricytochrome c formed by ferricytochrome reduction was measured with a UV-visible Shimadzu UV-2401PC spectrophotometer. The content of $\mathrm{O}_{2}^{-}$at a low estimate was calculated by subtracting absorbance with SOD from that without SOD at $550 \mathrm{~nm}\left(\varepsilon=21.1 \times 10^{3} \mathrm{M}^{-1}\right.$ $\mathrm{cm}^{-1}$ ) [28].

\subsection{DNA Binding Study by Fluorescence Spectroscopy}

A stock solution of ct-DNA was prepared by dissolving the solid material in $10 \mathrm{mM}$ phosphate buffer ( $\mathrm{pH} 7.0$ ) containing $50 \mathrm{mM}$ $\mathrm{NaCl}$ and stirred for $12 \mathrm{~h}$ at $4{ }^{\circ} \mathrm{C}$ in the dark. The concentration of DNA was determined by UV absorbance at $260 \mathrm{~nm}$ using the molar absorption coefficient $\varepsilon=260\left(6600 \mathrm{M}^{-1} \mathrm{~cm}^{-1}\right)$ [29]. The competitive binding experiment was carried out by maintaining the EB and ct-DNA concentration at $5 \mu \mathrm{M}$ and $55.7 \mu \mathrm{M}$, respectively, while increasing the concentration of the different compounds. The fluorescence spectra of a series of solutions with various concentrations of the derivative and a constant EB-ct-DNA complex were measured. All the fluorescence data were corrected for absorption of exciting and emitted light according to the relationship Eq. (1) [30]:

$\mathrm{FC}=\mathrm{Fm} \times e^{(\mathrm{A} 1+\mathrm{A} 2) / 2}$

where Fc and Fm are the corrected and measured fluorescence, respectively. A1 and A2 are the values of absorbance of climacostol and analogues at the exciting and emission wavelengths. Fluorescence quenching spectra were recorded using an ISS-Greg 200 spectrofluorimeter with an excitation wavelength of $500 \mathrm{~nm}$ and emission spectrum at $520-700 \mathrm{~nm}$. For fluorescence quenching experiments, the Stern_Volmer's Eq. (2) was used [31]:

$F_{0} / F=1+K_{Q} \tau_{0} 1 / 2[$ Ligand $]=1+K_{\mathrm{SV}}[$ Ligand $]$

where $F_{0}$ and $F$ represent the fluorescence intensity in the absence and in the presence of drug. [Ligand] is the concentration of the derivative and $K_{\mathrm{SV}}$ is the Stern_Volmer constant which is equal to $k_{Q} \tau_{0}$, where $k_{Q}$ is the bimolecular quenching rate constant and $\tau_{0}$ is the average fluorescence lifetime of the fluorophore in the absence of drug.

\subsection{UV-visible spectra measurements}

UV-visible spectra were measured at room temperature with a Shimadzu UV-2401PC spectrophotometer. A solution of $100 \mu \mathrm{M}$ of climacostol in PBS buffer was prepared, with a final volume of $3 \mathrm{ml}$ and the spectral tracing was started by addition of $200 \mu \mathrm{M} \mathrm{CuCl}_{2}$. The spectra were recorded every $5 \mathrm{~min}$ after addition of $\mathrm{CuCl}_{2}$.

\subsection{MS detection of products for the reaction of climacostol}

Analyses were carried out using liquid chromatographyelectrospray ionization tandem mass spectrometry (LC-ESI-MS). ESI-API low resolution mass spectra were recorded using an Agilent 1100 MSD ion trap mass spectrometer equipped with a standard ESI-API source. Nitrogen served both as the nebulizer gas and the dry gas. The samples were prepared by mixing $100 \mu \mathrm{M}$ of climacostol and $200 \mu \mathrm{M} \mathrm{CuCl}_{2}$ in $3 \mathrm{ml}$ of $10 \mathrm{mM}$ ammonium acetate buffer, and introduced by direct infusion with a syringe pump. Ammonium acetate is employed commonly in LC-MS because the ammonium plays the role of a volatile MS-friendly co-ion, instead of sodium or potassium. Also, for optimum MS analysis, ammonium acetate works as ionization reagent.

\subsection{Statistical analysis}

Data represent the mean \pm standard error (S.E.), unless otherwise indicated, of three independent experiments. The significance of the differences between the mean values was examined by Student's $t$-test. The minimum level of significance considered was $P<0.05$. 


\section{Results}

\subsection{Strand breakage of plasmid pBR322 DNA induced by climacostol in} presence of $\mathrm{Cu}(\mathrm{II})$

The destruction of the supercoiled pBR322 DNA and formation of the open circular and linear forms of DNA were used to assess the DNA strand breakage [23]. Cu(II) or climacostol alone with concentration up to $500 \mu \mathrm{M}$ (lanes 2 and 3 in Fig. 1A) were not able to cause detectable DNA damage. However, extensive DNA damage was caused by incubation of supercoiled pBR322 DNA in presence of both climacostol and $\mathrm{Cu}$ (II) in a concentration-dependent manner (lanes 4-8 in Fig. 1A). Fig. 1B shows the dependence of the reaction from the $\mathrm{Cu}(\mathrm{II})$ concentration. The molar ratio of climacostol to $\mathrm{Cu}(\mathrm{II})$ should be approximately $1: 1$ to effectively induce DNA damage. Cisplatin, an anticancer drug used in chemotherapy because it can bind to and damage the DNA in cell systems, was assayed in the same test, and negative results were obtained (data not show).

\subsection{Identification of ROS involved in DNA damage induced by climacostol and $\mathrm{Cu}(\mathrm{II})$}

To clarify the roles of oxygen-derived active species in the DNA strand breakage induced by climacostol in presence of $\mathrm{Cu}(\mathrm{II})$, attempts were made to prevent the DNA strand breakage with free radical scavengers (Fig. 2). Typical hydroxyl radical scavengers such as DMSO and mannitol, an $\cdot \mathrm{OH}$ scavenger, showed little or no inhibitory effect on DNA damage (lanes 6 and 8 in Fig. 2A). However, catalase, an $\mathrm{H}_{2} \mathrm{O}_{2}$ scavenger, and SOD, an $\mathrm{O}_{2}^{--}$scavenger, prevented the DNA damage induced by climacostol. Catalase was able to inhibit DNA breakage almost completely at the concentration of $50 \mathrm{U} / \mathrm{ml}$ (Fig. 2B). $\mathrm{O}_{2}^{-}$was investigated by cytochrome $\mathrm{c}$ reduction. In the climacostol and $\mathrm{Cu}(\mathrm{II})$ system, cytochrome $\mathrm{C}$ was actually reduced, and this reduction was inhibited in the presence of SOD due to the conversion of $\mathrm{O}_{2}^{--}$into $\mathrm{H}_{2} \mathrm{O}_{2}$. The amount of $\mathrm{O}_{2}^{--}$generation could be estimated from the difference in cytochrome $\mathrm{c}$ reduction with and without SOD. Fig. $2 \mathrm{C}$ reports the rate of reduction of cytochrome $c$ by climacostol, which increased in 10 min, indicating that the $\mathrm{O}_{2}^{--}$was generated in a relatively short time compared with DNA damage. The presence of SOD in the incubation mixture almost completely lowered climacostol's activity in reducing cytochrome c. In comparison with the cytochrome c reduction activity of caffeic acid, a dihydroxyl phenolic compound

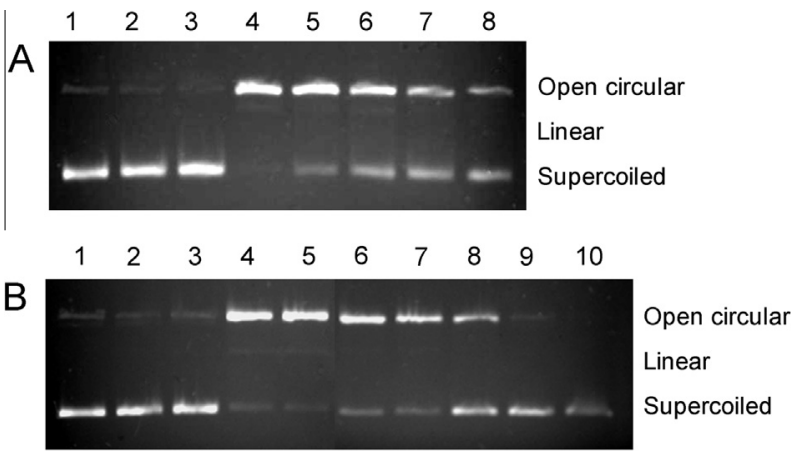

Fig. 1. Concentration dependence of climacostol on pBR322 DNA strand breakage in presence of $\mathrm{Cu}(\mathrm{II})$. Supercoiled pBR322 DNA (180 ng) was incubated with climacostol with/without $100 \mu \mathrm{M} \mathrm{Cu}$ (II) in PBS for $1 \mathrm{~h}$ at $37^{\circ} \mathrm{C}$. (A) Lane 1: native DNA; Lane 2: $\mathrm{Cu}(\mathrm{II})$ alone $(100 \mu \mathrm{M})$; Lane 3: climacostol alone $(500 \mu \mathrm{M})$; Lanes 4-8: climacostol $/ \mathrm{Cu}(\mathrm{II}) 100,50,25,12.5,6.25 \mu \mathrm{M} / 100 \mu \mathrm{M}$. (B) Concentration dependence of $\mathrm{Cu}(\mathrm{II})$ on climacostol-Cu(II)-mediated DNA strand breakage. Lane 1: native DNA; Lane 2: climacostol alone $(100 \mu \mathrm{M})$; Lane 3: $\mathrm{Cu}(\mathrm{II})$ alone $(200 \mu \mathrm{M})$; Lanes 4 10: $\mathrm{Cu}(\mathrm{II}) /$ climacostol 200, 100, 50, 25, 12.5, 6.25, $3.125 \mu \mathrm{M} / 100 \mu \mathrm{M}$.
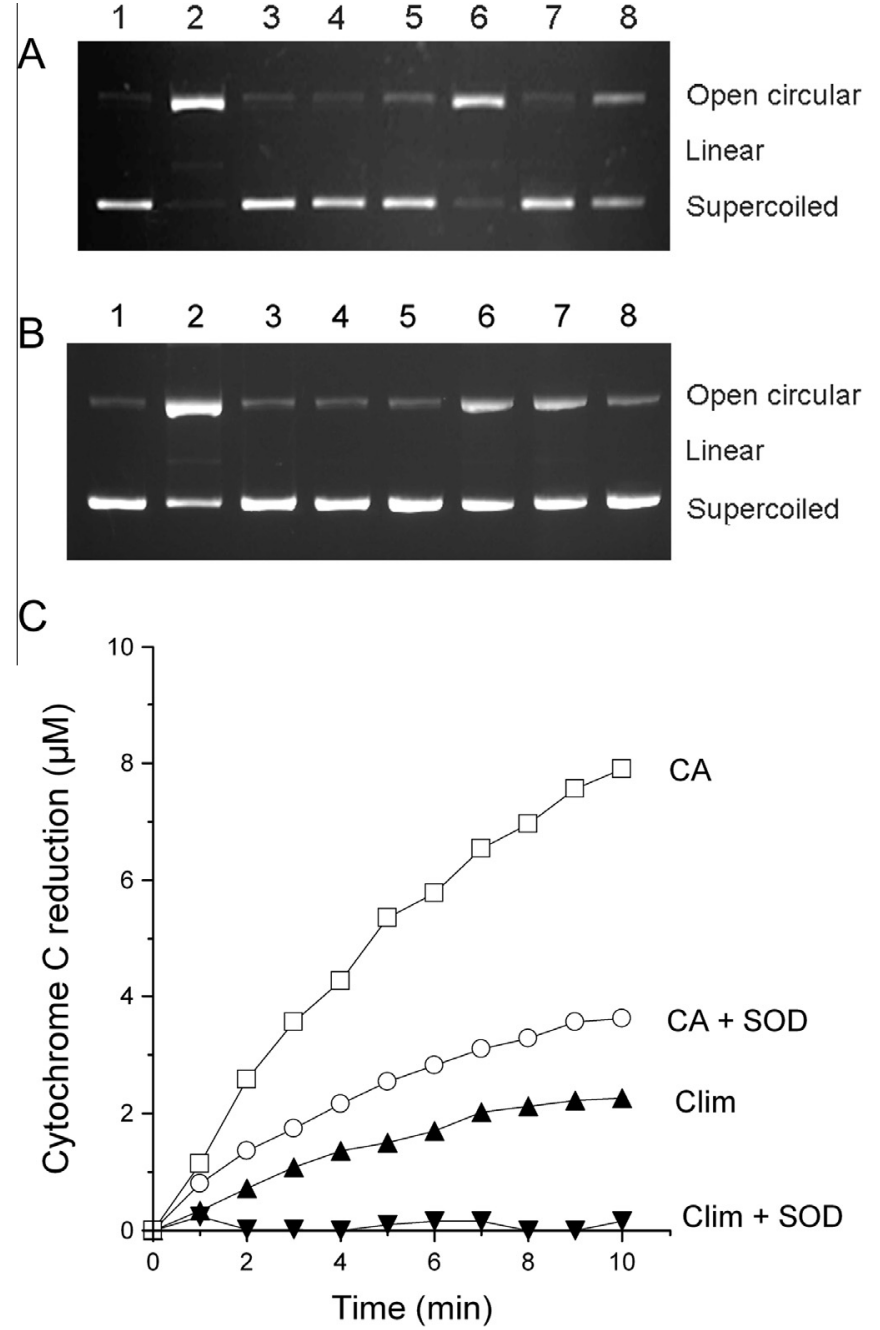

Fig. 2. Identification of ROS involved in DNA damage induced by climacostol and $\mathrm{Cu}(\mathrm{II})$. The experimental conditions are the same as described in Fig. 1. (A) Lane 1: native DNA; Lane 2: climacostol/ $\mathrm{Cu}$ (II) $100 \mu \mathrm{M} / 100 \mu \mathrm{M}$; Lane 3: EDTA/Cu(II) $2 \mathrm{mM}$ / $100 \mu \mathrm{M}$; Lane 4: climacostol/EDTA/Cu(II) $100 \mu \mathrm{M} / 2 \mathrm{mM} / 100 \mu \mathrm{M}$; Lane 5: mannitol/ $\mathrm{Cu}$ (II) $100 \mathrm{mM} / 100 \mu \mathrm{M}$; Lane 6: climacostol/mannitol/Cu(II) $100 \mu \mathrm{M} / 100 \mathrm{mM} /$ $100 \mu \mathrm{M}$; Lane 7: DMSO/Cu(II) $10 \% / 100 \mu \mathrm{M}$; Lane 8: climacostol/DMSO/Cu(II) $100 \mu \mathrm{M} / 10 \% / 100 \mu \mathrm{M}$. (B) Lane 1: native DNA; Lane 2: climacostol/ $\mathrm{Cu}(\mathrm{II})$ $100 \mu \mathrm{M} / 100 \mu \mathrm{M}$; Lane 3-5: catalase/Cu(II) $12.5,25,50 \mathrm{U} / \mathrm{ml}$; Lanes 6-8: climacostol/catalase/Cu(II) $100 \mu \mathrm{M} / 12.5,25$, and $50 \mathrm{U} / \mathrm{ml} / 100 \mu \mathrm{M}$. (C) Time course of generation of $\mathrm{O}_{2}^{--}$during climacostol and $\mathrm{Cu}(\mathrm{II})$ treatment in presence and absence of SOD. Reaction mixtures contained $40 \mu \mathrm{M}$ cytochrome $\mathrm{c}$ and $100 \mu \mathrm{M}$ climacostol in presence of $100 \mathrm{U} / \mathrm{ml}$ in $10 \mathrm{mM}$ phosphate buffer (pH 7.8). A maximum absorption at $550 \mathrm{~nm}$ was measured at $37^{\circ} \mathrm{C}$ with UV-visible spectrophotometer every $1 \mathrm{~min}$ for $10 \mathrm{~min}$. Clim, climacostol; CA, caffeic acid. The results are representative of three independent experiments and mean values are plotted.

like climacostol, but with a different oxydrilic group disposition in the phenolic ring, the reduction activity of climacostol produces less $\mathrm{O}_{2}^{--}$. The high efficacies of catalase and SOD indicate that peroxide and superoxide are the primary reactive oxygen species formed in this system. The less efficacious hydroxyl radical scavengers indicate that these reactive oxygen species may be formed secondarily.

\subsection{Reduction of $\mathrm{Cu}(\mathrm{II})$ by climacostol}

Confirmation of climacostol's dependence on $\mathrm{Cu}$ (II) for its oxidant activity also was seen with the inhibition of DNA breakage in the presence of EDTA (lane 4 in Fig. 2A). A probable mechanism for DNA cleavage would involve the reduction of $\mathrm{Cu}(\mathrm{II})$ to $\mathrm{Cu}(\mathrm{I})$. To 
explore this, the effect of neocuproine, a $\mathrm{Cu}(\mathrm{I})$-specific sequestering agent, on the reduction of $\mathrm{Cu}(\mathrm{II})$ by climacostol was investigated. Increasing concentrations of neocuproine in the mixture solution inhibited DNA damage by climacostol (Fig. 3A). The formation of a reduced form of $\mathrm{Cu}(\mathrm{I})$ in the reaction was confirmed by the increasing absorbance at $450 \mathrm{~nm}$ of the neocuproine- $\mathrm{Cu}(\mathrm{I})$ complexes formed by incubating different concentrations of climacostol in the presence of $\mathrm{Cu}$ (II) (Fig. $3 \mathrm{~B}$ ). The results suggest that the reduction of $\mathrm{Cu}(\mathrm{II})$ to $\mathrm{Cu}(\mathrm{I})$ is essential for DNA cleavage activity by climacostol.

\subsection{UV-visible and mass spectral changes of climacostol in the presence of $\mathrm{Cu}(\mathrm{II})$}

In order to clarify the mechanism of the DNA damage, the UVvisible absorption changes of climacostol in the presence of $\mathrm{Cu}(\mathrm{II})$ were examined. As reported in Fig. 4, when $\mathrm{Cu}(\mathrm{II})$ was added to climacostol in PBS buffer ( $\mathrm{pH} 7.4)$ under aerobic conditions, the absorption of climacostol decreased, highlighting two peaks at $273 \mathrm{~nm}$ and $279 \mathrm{~nm}$. The change of absorption spectra suggests a structure modification in the native climacostol. Mass spectrometric analysis was performed to identify the products of the reaction. Most spectrometric measurements are done in positive ion mode, which is accomplished by the addition of a proton to form the molecular ion $[\mathrm{M}+\mathrm{H}]^{+}$. However, our mixture resulted in very complicated mass spectra that were difficult to solve. Since metal ions such as $\mathrm{Cu}^{2+}$ are particularly problematic in positive ion mode, as they interfere strongly with LC-MS, causing higher background noise and the formation of adducts, we evaluated mass spectra in the negative ion mode as an alternative approach, and report here the $[\mathrm{M}-\mathrm{H}]^{-}$ions of species present in the mixture. When climacostol was incubated with $\mathrm{Cu}(\mathrm{II})$, the initial mass spectra was characterized by a prominent $[\mathrm{M}-\mathrm{H}]^{-}$ion at $\mathrm{m} / \mathrm{z} 233$, corresponding nominally to deprotonated climacostol. We observed traces of a peak at $m / z 247$, and, quite interestingly, noted that during the incubation, the peak at $\mathrm{m} / \mathrm{z} 233$ decreased in intensity, while the

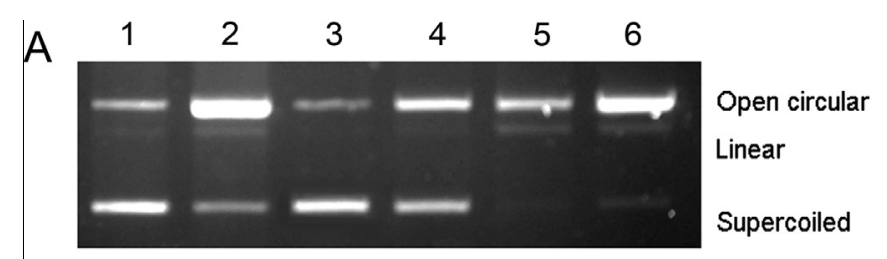

B

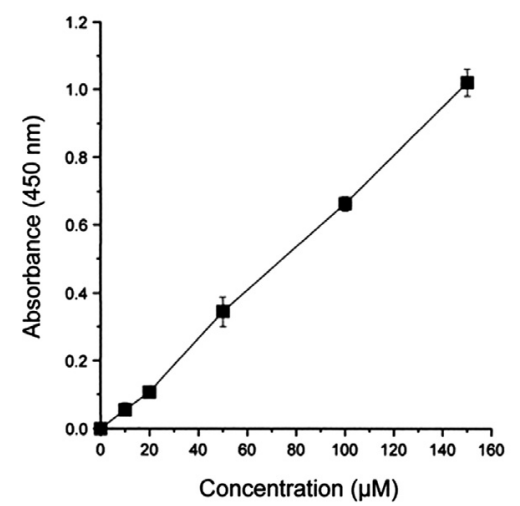

Fig. 3. Effect of neocuproine on climacostol-Cu(II)-mediated DNA strand breakage. (A) Lane 1: native DNA; Lane 2: climacostol/ Cu(II) $100 \mu \mathrm{M} / 100 \mu \mathrm{M}$; Lanes 3-6: climacostol/neocuproine/Cu(II) $100 \mu \mathrm{M} / 800,400,200,100 \mu \mathrm{M} / 100 \mu \mathrm{M}$. (B) Formation of $\mathrm{Cu}(\mathrm{I})$. The mixture solution contained increasing concentration of climacostol in presence of neocuproine $(800 \mu \mathrm{M})$ and $\mathrm{Cu}(\mathrm{II})(100 \mu \mathrm{M})$ in PBS buffer $(\mathrm{pH}$ 7.4). The results represent of three independent experiments and mean values are plotted.

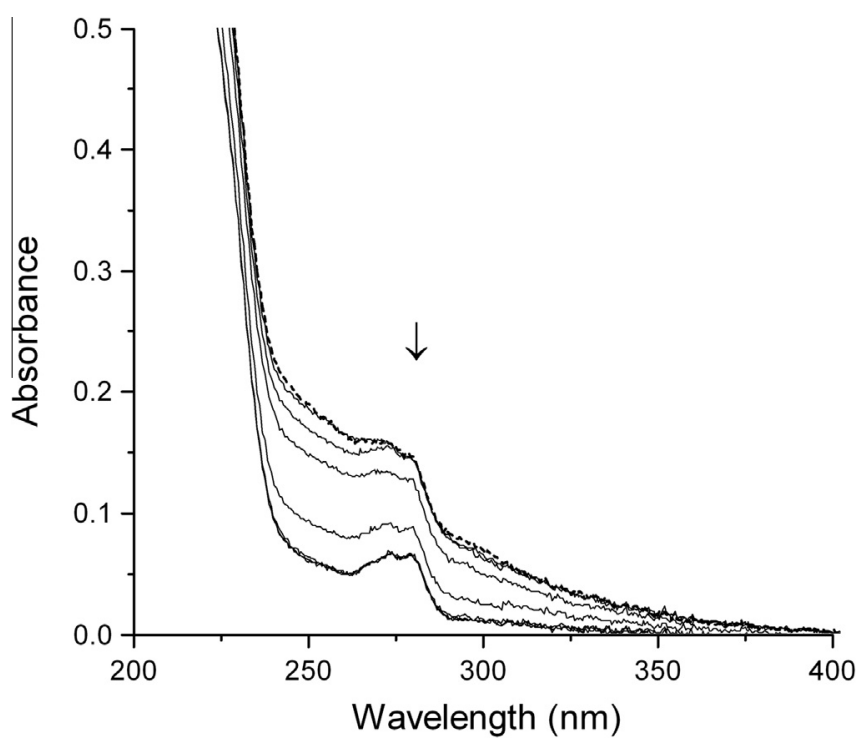

Fig. 4. Absorption spectral changes of climacostol $(100 \mu \mathrm{M})$ in absence (dash line) and in presence (solid line) of $200 \mu \mathrm{M}$ of $\mathrm{Cu}$ (II) in PBS buffer ( $\mathrm{pH} 7.4$ ) under air. The spectra were recorded every $5 \mathrm{~min}$ for $30 \mathrm{~min}$ after addition of $\mathrm{Cu}(\mathrm{II})$. Arrow shows the time-related absorbance changes.

peak at $m / z 247$ increased in intensity (Table 1 ). Therefore, it is possible that the negative ion at $m / z 247$ (Fig. 6), corresponding to a deprotonated species, derived from climacostol. In fact, Sayre et al. [32] reported that naturally occurring 5-alkenylresorcinols undergo oxygenation in the presence of $\mathrm{Cu}(\mathrm{II})$. We believe that in non-acidic conditions $\mathrm{Cu}^{2+}$ can catalyse the autoxidative oxygenation of climacostol, thus producing the corresponding 5-(2-nonenyl)-2-hydroxy-1,4-benzoquinone (2) (Scheme 1). The negative ion at $m / z 247$ is accomplished by the deprotonation of 2 to form the molecular ion $[\mathrm{M}-\mathrm{H}]^{-}$.

In order to compare the oxidant activity of climacostol with its analogous compounds, we assayed resorcinol, orcinol and olivetol for their DNA breakage capability. The analogues were incubated with plasmid DNA in presence of $\mathrm{Cu}(\mathrm{II})$ in the same molar concentration as that used for climacostol. The analogues were able to induce breakage of DNA, as shown in Fig. 5A, but with lower activity than climacostol. To explain this result, we studied the interaction of climacostol and its analogues with DNA. First, climacostol's DNA breakage capability on eukaryotic DNA was analyzed. Fig 5B shows that climacostol is able to degrade the double strand of calf thymus DNA in a dose-dependent manner after $6 \mathrm{~h}$ of incubation in presence of $\mathrm{Cu}(\mathrm{II})$. To prove or rule out the possibility of a DNA-drug interaction, a competitive ethidium bromide (EB) binding assay was undertaken to understand the mode of ct-DNA interaction with climacostol and it's analogous. The fluorescence spectra for the interaction of the different compounds with EB-ct-DNA at

Table 1

Mass-spectrometry data for the reaction of climacostol with $\mathrm{Cu}(\mathrm{II})$.

\begin{tabular}{rll}
\hline Time $(\min )$ & {$[\mathrm{M}-\mathrm{H}]^{-}$} & \\
\cline { 2 - 3 } & $233.0(\%)$ & $247.0(\%)$ \\
\hline 0 & 100 & 3.5 \\
5 & 100 & 40 \\
10 & 100 & 69.3 \\
20 & 100 & 91.3 \\
30 & 75.6 & 100 \\
\hline
\end{tabular}

Climacostol $(100 \mu \mathrm{M})$ and of $\mathrm{CuCl}_{2}(200 \mu \mathrm{M})$ were incubated in $10 \mathrm{mM}$ ammonium acetate buffer ( $\mathrm{pH} 7.4$ ) and aliquots were injected for MS detection at different time. Abundances were normalized to the most abundant product ion. 
<smiles>CCCCC/C=C/Cc1cc(O)cc(O)c1</smiles><smiles>CCCCC/C=C/C/C=C/C1=CC(=O)C=C(O)C1=O</smiles>

Scheme 1. API-ESI mass spectrum in negative ion mode of climacostol, $\mathrm{CuCl} 2$, and ammonium acetate buffer.
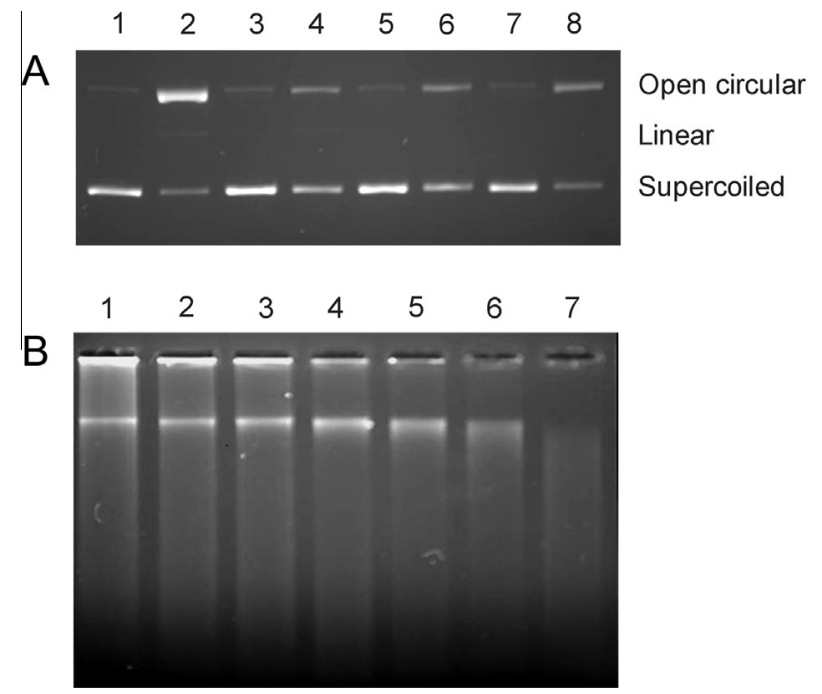

Fig. 5. Effect of climacostol and its analogues on $\mathrm{Cu}(\mathrm{II})$-mediated degradation of pBR322 DNA. The conditions were the same of Fig. 1. (A) Lane 1: native DNA; Lane 2: climacostol/ $\mathrm{Cu}$ (II) $100 \mu \mathrm{M} / 100 \mu \mathrm{M}$; Lane 3: olivetol $100 \mu \mathrm{M}$; Lane 4: olivetol/ $\mathrm{Cu}$ (II) $100 \mu \mathrm{M} / 100 \mu \mathrm{M}$; Lane 5: orcinol $100 \mu \mathrm{M}$; Lane 6: orcinol/Cu(II) $100 \mu \mathrm{M} /$ $100 \mu \mathrm{M}$; Lane 7: resorcinol $100 \mu \mathrm{M}$; Lane 8: resorcinol/Cu(II) $100 \mu \mathrm{M} / 100 \mu \mathrm{M}$. (B) Effect of climacostol on $\mathrm{Cu}(\mathrm{II})$-mediated degradation of calf thymus DNA. DNA was incubated at $37^{\circ} \mathrm{C}$ for $2 \mathrm{~h}$ (Lanes 2-4) and $6 \mathrm{~h}$ (Lanes 5-7) with different concentrations of climacostol $(250,500$, and $1000 \mu \mathrm{M})$ in presence of $100 \mu \mathrm{M}$ $\mathrm{Cu}(\mathrm{II})$ in PBS buffer ( $\mathrm{pH}$ 7.4) under air. Lane 1: $6 \mathrm{~h}$ incubation of DNA without climacostol.

$298 \mathrm{~K}$ are shown in Fig. 7. EB-ct- DNA exhibits a strong fluorescence emission at $597 \mathrm{~nm}$ on excitation at $500 \mathrm{~nm}$. All the tested compounds have negligible fluorescence under these experimental conditions. Even so, to avoid any contribution from ligands to the fluorescence of EB-ct-DNA, control sets were subtracted. Addition of different compounds to EB-ct-DNA led to a significant quenching of the fluorescence intensity of EB-ct-DNA (Fig. 7A) and, according to Eq. (2), for fluorescence quenching of EB-ct-DNA (Fig. 7B), the Stern_Volmer quenching constant $K_{\mathrm{SV}}$ was obtained by the slope of the regression curve in the linear range. Data for the quenching constants for the interaction for all the studied compounds are reported in Table 2. Generally, the linearity of the Stern_Volmer plot may have two meanings: the existence of one binding site for the ligand in the proximity of the fluorophore, or more than one binding site equally accessible to the ligand. In the case of fluorescence caused only by EB-ct-DNA, assuming that the complex (compound/ct-DNA) was not fluorescent and that there was a 1:1 stoichiometry of binding, the observed change in fluorescence of EB-ct-DNA, after binding with increasing concentrations of compounds, can be related to the following Eq. (3) [33]:

$\log \left({ }_{F 0}-F\right) / F=n \log _{K A}+n \log \left([\right.$ Ligand $]-[$ EB-ct-DNA $]\left({ }_{F 0}-F\right) / F 0$

where [EB-ct-DNA] and [Ligand] were the total concentration of EB-ct-DNA and different compounds tested, $\mathrm{K}_{\mathrm{A}}$ and $\mathrm{n}$ are the binding constant and the number of binding sites, respectively. On the basis of the assumption, the plot of $\log \left(F_{0}-F\right) / F$ versus $\log \left(1 /\left([\right.\right.$ Ligand] $]-\left([\right.$ EB-ct-DNA $\left.\left.]\left(F_{0}-F\right) / F_{0}\right)\right)$ was drawn (Fig. 7B) and fitted linearly, and the value of $n$ (number of binding sites) and the value of $K_{A}$ were obtained. Values of binding constants obtained for the different compounds are reported in Table 2. From the values of the $K_{\mathrm{SV}}$ and $K_{A}$ constants, related to the binding of the compounds to DNA, we can see that climacostol and resorcinol showed the higher binding activity on DNA while the interaction of orcinol was lower than the other compounds tested. Binding activity on DNA followed the sequence climatostol $\geqslant$ resorcinol $>$ olivetol $>$ orcinol.

\section{Discussion}

\subsection{Structure-activity relationship and reaction mechanism}

The unsaturation in the alkyl substituent of climacostol may facilitate DNA cleavage. Since several DNA minor-groove binding agents have been shown to associate with DNA via hydrophobic interactions, it is possible that the double bond imparts an orientation to the alkyl substituent conducive to hydrophobic association in the minor-groove of DNA. Most importantly, it has been observed that the DNA cleavage for 5-alkenyl resorcinols in the presence of $\mathrm{Cu}(\mathrm{II})$ must involve initial hydroxylation of the benzene

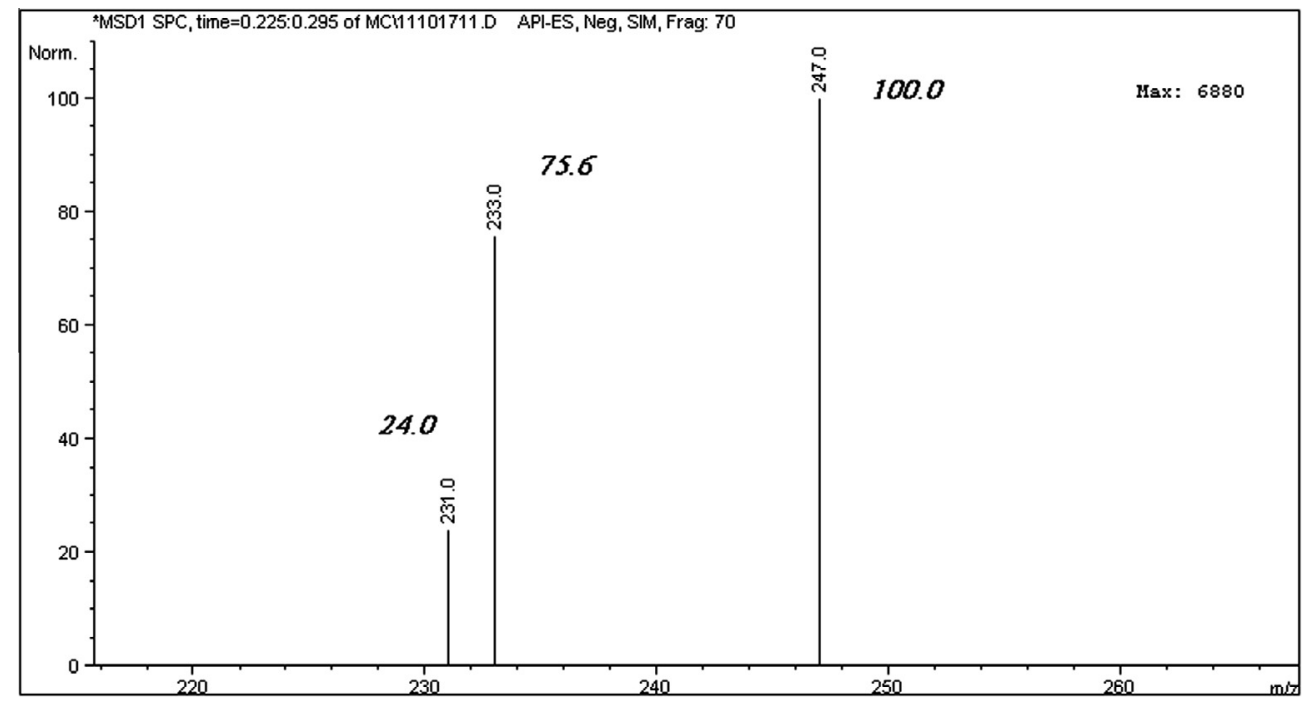

Fig. 6. Oxygenation of the benzene nucleus in climacostol (1) 

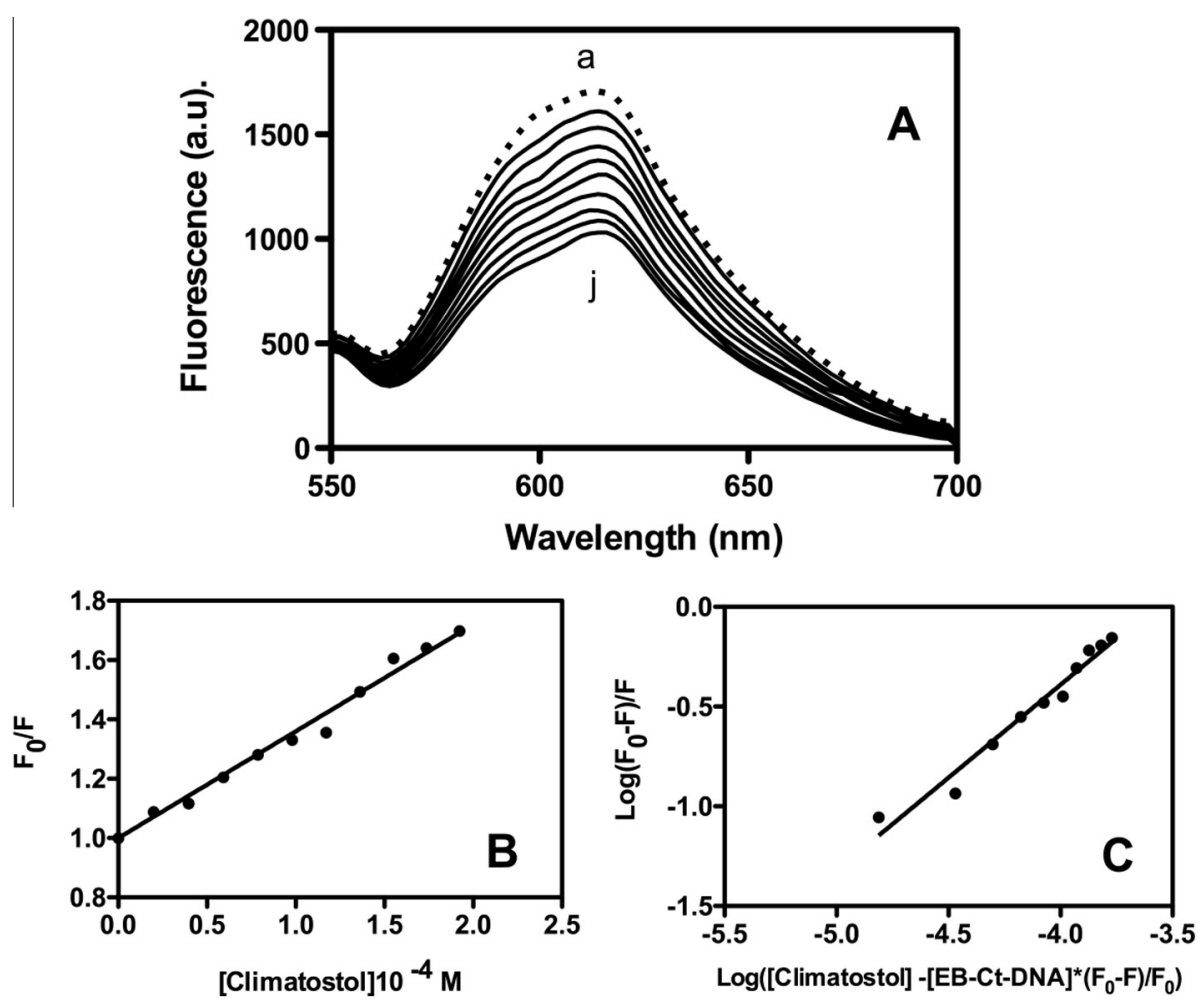

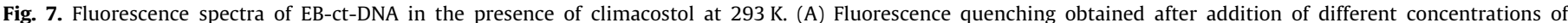

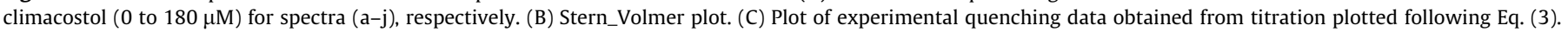

Table 2

Binding constants of climacostol and other derivatives with EB-DNA.

\begin{tabular}{llll}
\hline Compound & $K_{\mathrm{sv}} 10^{3} \mathrm{M}^{-1}$ & $K_{A} 10^{3} \mathrm{M}^{-1}$ & $n$ \\
\hline Climacostol & $3.60( \pm 0.01)$ & $3.82( \pm 0.08)$ & $0.931( \pm 0.06)$ \\
Olivetol & $1.93( \pm 0.04)^{\mathrm{a}}$ & $2.85( \pm 0.04)^{\mathrm{a}}$ & $1.23( \pm 0.05)$ \\
Orcinol & $0.96( \pm 0.03)^{\mathrm{a}}$ & $0.65( \pm 0.02)^{\mathrm{a}}$ & $0.84( \pm 0.07)$ \\
Resorcinol & $2.97( \pm 0.01)^{\mathrm{a}}$ & $3.41( \pm 0.09)^{\mathrm{a}}$ & $1.06( \pm 0.06)$ \\
\hline
\end{tabular}

Ct-DNA $(55.7 \mu \mathrm{M})$ and ethidium bromide $(5 \mu \mathrm{M})$ in $10 \mathrm{mM}$ phosphate buffer $(\mathrm{pH} 7.0)$ containing $50 \mathrm{mM} \mathrm{NaCl}$ were put in presence of climacostol or analogues $(0-180 \mu \mathrm{M})$ and fluorescence spectra were measured.

Data represent the mean ( \pm S.E.) from three independent experiments.

a $P<0.05$; analogous vs. climacostol.

ring [34]. Oxygenation of the aromatic nucleus affords catecholic moieties that can act as bidentate ligand for $\mathrm{Cu}(\mathrm{II})$ [23].

The finding that $\mathrm{Cu}(\mathrm{I})$ is an obligatory intermediate in DNA cleavage mediated by climacostol and that oxygenation in the aromatic moiety is also required, suggested that the reactive species actually responsible for DNA cleavage may be a hydroxyl radical (HO) generated from $\mathrm{O}_{2}$ at the metal centre. It has been suggested that a trihydroxylated species acts as an intermediary in the initial hydroxylation of the benzene ring of climacostol; if it is so, it would support the thesis that $\mathrm{HO}$ mediates DNA cleavage by the 5-alkenylresorcinols [24]. However, in LC-MS analysis the absence of the $[\mathrm{M}-\mathrm{H}]^{-}$ion at $m / z 249$, corresponding nominally to 6 -nonenyl-1,2,4-trihydroxybenzene, means that the ease with which climacostol facilitates DNA cleavage is not due to initial hydroxylation. Given these results, we suggest a new possible mechanism, in which one-electron oxidation of $\mathrm{Cu}$ (II) catalyzed by the climacostol, followed by reaction with $\mathrm{O}_{2}$, is responsible for the formation of a hydroperoxide radical 7 (Scheme 2). Rearrangement of this intermediate and homolytic cleavage of the peroxide bond affords HO and the 2-hydroxy-1,4-benzoquinone derivative $\mathbf{2}$. In this reaction the $\mathrm{Cu}(\mathrm{II}) / \mathrm{Cu}(\mathrm{I})$ redox cycle can plays an important role in DNA damage, since initial transfer oxidation of climacostol by $\mathrm{Cu}(\mathrm{II})$ generates the corresponding radical 4 and $\mathrm{Cu}(\mathrm{I})$, which undergoes a second electron transfer with $\mathrm{O}_{2}$ to form $\mathrm{O}_{2}^{-}$. The $\mathrm{O}_{2}^{--}$reacts with $\mathrm{Cu}(\mathrm{II})$, giving hydrogen peroxide, which is readily converted by a Fenton-type reaction to a hydroxyl radical to induce oxidative DNA damage. This proposed mechanism is supported by the observation of the negative ion at $m / z 231$ (Fig. 6), corresponding to compound $\mathbf{1 0}$ (Scheme 3 ) which could be explained by a cyclization reaction that involves the radical intermediate $\mathbf{5}$. In fact, it is known that intramolecular addition of the radical $\mathbf{5}$ to the exocyclic double bond gives the thermodynamically stable carbon radical 8 [35] by 5-endo-trig cyclization, because, conversely to ionic species, the radicals are not subject to elimination of $\beta-\mathrm{H}$. Consequently, through the presence of $\mathrm{Cu}(\mathrm{II}), \mathbf{8}$ undergoes transformation to the corresponding carbocation 9, which subsequently generates the compound observed in LC-MS analysis [36]. A possible explanation for the presence of the product $\mathbf{1 0}$ could be that an elimination occurs through an electron transfer process.

\subsection{Implications for anticancer properties}

DNA-targeted chemotherapies are fundamental in clinical management of common solid tumours and hematologic malignancies. Although cisplatin is a widely used anticancer drug, its clinical usefulness has been limited due to the frequent development of drug resistance and severe side effects [43]. The search for a more selective and efficacious drugs that can deliver critical DNA damage with minimal side effects continues [44]. Numerous reports have indicated that resorcinolic lipids and, more in general, phenolic lipids, exert a direct effect on the structure and metabolism of nucleic acids, both in prokaryotic and eukaryotic systems [for reviews, see $[5,37]]$. In particular, numerous natural and synthetic compounds belonging to this class of lipids are capable of inducing nuclear and/or mitochondrial DNA damage and, in turn, programmed cell death (PCD), and thus have been investigated extensively as cytotoxic and anticancer agents. 


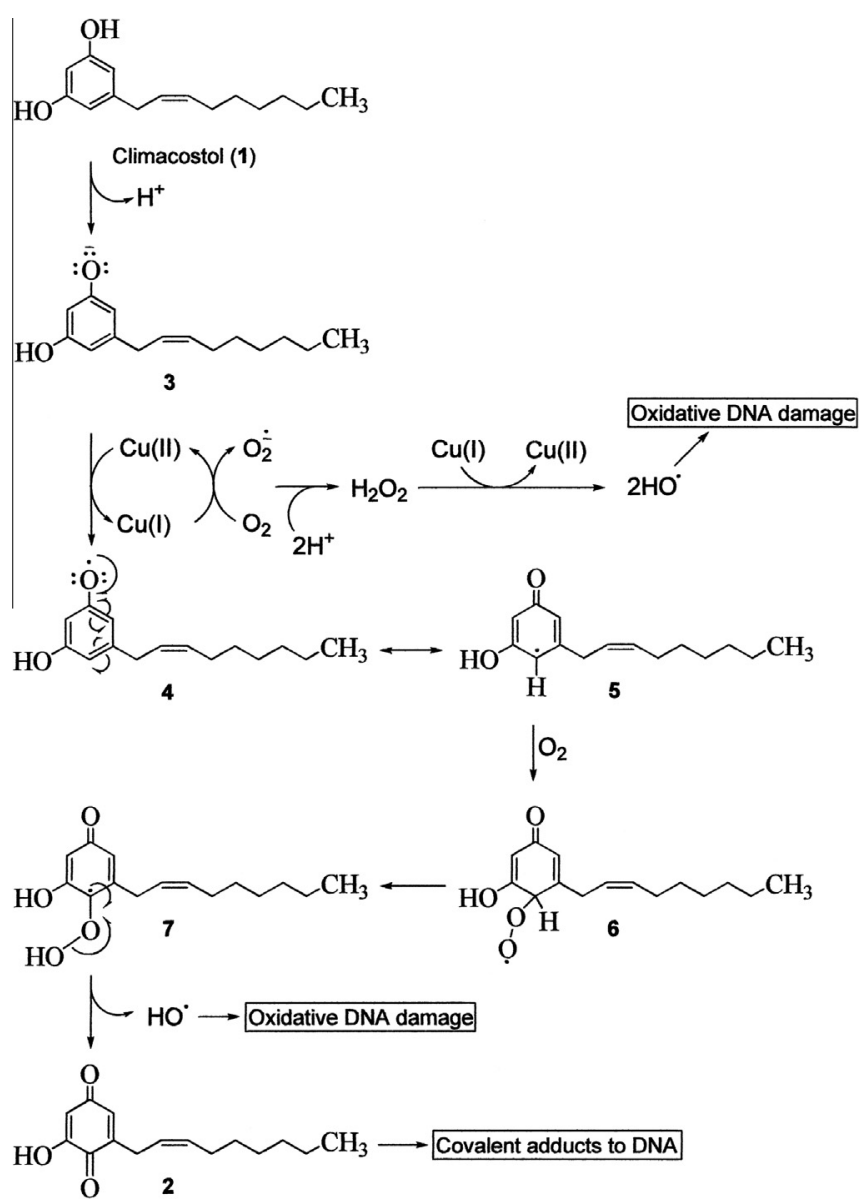

Scheme 2. Mechanism of oxidative DNA damage induced by climacostol in presence of $\mathrm{Cu}(\mathrm{II})$. 5-Endo-Trig ring closure in radical cyclization process: thermodynamically products.

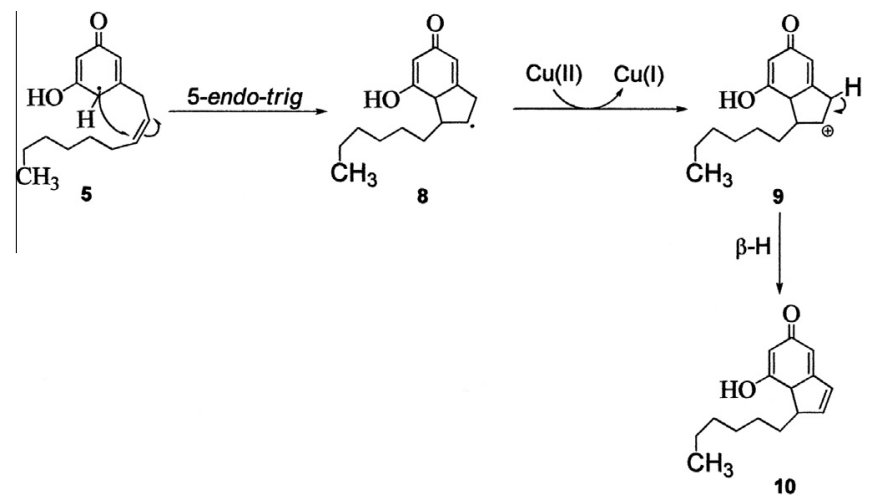

Scheme 3. 5-Endo-trig ring closure in radical cyclization process: thermodynamically products.

It appears that this spectrum of activities also occurs with climacostol, which some of us have recently found to exert a cytotoxic effect on a panel of human cancer cell lines (HL60, A431, PC-3, T98G, and U87MG), with activation of either apoptotic or apoptotic-like cell death, and negligible effect on non-tumor cells. Interestingly, climacostol was found to injure mitochondria in cancer cells with the activation of apoptosis-promoting caspases, in HL60 cells, the loss of mitochondrial membrane potential $\left(\Delta \Psi_{m}\right)$ was in fact coupled with ROS generation [18].
The data collected in this work builds upon these observations with evidence that climacostol can effectively bind both plasmid and nuclear DNA, and promote their cleavage by generating ROS in the presence of $\mathrm{Cu}$ (II).

The relationship between ROS generation, DNA damage, apoptosis and carcinogenesis has been investigated extensively [for reviews, see [38,39]]. In particular, it has been reported that cells exposed to strong DNA damage, as in the case of cleavage by ROS, usually undergo apoptosis, whereas cells that undergo weak DNA damage and fail to repair it can accumulate mutations leading to carcinogenesis [28].

Interestingly, the prooxidant action of some metal-chelating compounds and plant polyphenols has been indicated as an important mechanism for their proapoptotic and anticancer properties $[40,41]$. In fact, it was demonstrated that these compounds promote the redox activity of endogenous copper ions (possibly those bound to chromatin) triggering ROS generation, which in turn can lead to non-enzymatic internucleosomal DNA cleavage. The damaged chromatin can be eventually fragmented by agarose-gel electrophoresis, resulting in a typical "DNA laddering", a trait usually indicated as a hallmark of apoptosis, and which we observed in four human cancer cell lines exposed to climacostol $[9,18]$. In these cell lines, climacostol quickly increased the levels of initiator caspase- 9 and executioner caspase- 3 , suggesting the activation of a canonical mitochondrion-dependent apoptotic program, with enzymatic degradation of nuclear DNA. Nevertheless, in the light of the results described in this paper, we cannot exclude that non-enzymatic DNA cleavage could reinforce the enzymatic one, thus playing an important role in explaining the preferential cytotoxicity of climacostol towards cancer cells. In fact, cancer cells usually have higher intracellular copper levels than normal cells, and consequently lower concentrations of climacostol would be required to drive them toward an apoptotic fate. However, the evidence that climacostol can interact with both histone-protected and naked DNA, damaging them extensively by inducing appreciable ROS generation, strongly suggests that mtDNA could represent a second important target for the toxin. In the case of human mtDNA codes for 13 respiratory chain subunits, seven of which are constituents of the electron transport chain complex I, it is possible that damage of the mitochondrial genome would overlap to the nuclear DNA damage, causing rapid and irreversible decline of organelle functions, and activation of the apoptotic program. It is also likely that it is easier for climacostol to cause oxidative cleavage of unprotected mtDNA than of nuclear DNA; a similar observation has been made for human hepatoma G2 cells exposed to curcumin [42], a prooxidant and pro-apoptotic polyphenol extracted from the root of Curcuma longa. Curcumin, in fact, has been demonstrated to induce oxidative damage to both nuclear and mtDNA, but the damage to mtDNA was more extensive than that to nuclear DNA.

In conclusion, climacostol can effectively mediate DNA damage in the presence of $\mathrm{Cu}(\mathrm{II})$. The antimicrobial and antiproliferative activity of climacostol and its apoptosis-inducing properties can be explained by its metal-reducing activity, which produces reactive oxygen species; these qualities may make it a potential resource for chemotherapeutic use.

\section{Conflict of interest statement}

The authors declare that there are no conflicts of interest.

\section{Acknowledgement}

We would like to thank the Ministero dell'Istruzione, dell'Università e della Ricerca (Grant N. 2009ACFPN9) for financial support. 


\section{References}

[1] A. Miyake, F. Buonanno, P. Saltalamacchia, M.E. Masaki, H. Ilo, Chemical defense by means of extrusive cortical granules in the heterotrich ciliate Climacostomum virens, Eur. J. Protistol. 39 (2003) 25-36.

[2] F. Buonanno, Variations in the efficiency of ciliate extrusomal toxins against a common ciliate predator, the catenulid Stenostomum sphagnetorum, Ital. J. Zool. 72 (2005) 293-295.

[3] S. Pucciarelli, F. Buonanno, G. Pellegrini, P. Ballarini, C. Miceli, Biomonitoring of Lake Garda: Identification of ciliate species and symbiotic algae responsible for the "black-spot" bloom during the summer of 2004, Environ. Res. 107 (2) (2008) 194-200.

[4] R.A. Barrow, R.J. Capon, Alkyl and alkenyl resorcinols from an Australian marine sponge, Haliclona sp. (Haplosclerida: Haliclonidae), Aust. J. Chem. 44 (1991) 1393-1405.

[5] A. Kozubek, J.H.P. Tyman, Resorcinolic lipids, the natural non-isoprenoid phenolic amphiphiles and their biological activity, Chem. Rev. 99 (1999) 1-25.

[6] M.E. Masaki, T. Harumoto, M.N. Terazima, A. Miyake, Y. Usuki, H. Iio, Climacostol, a defense toxin of the heterotrich ciliate Climacostomum virens against predators, Tetrahedron Lett. 40 (1999) 8227-8229.

[7] M.E. Masaki, S. Hiro, Y. Usuki, T. Harumoto, M.N. Terazima, F. Buonanno, A Miyake, H. Iio, Climacostol, a defense toxin of Climacostomum virens (protozoa, ciliata), and its congeners, Tetrahedron 60 (2004) 7041-7048.

[8] Y. Abe, K. Mori, Simple synthesis of climacostol, a defensive secretion by the ciliate Climacostomum virens, Biosci. Biotechnol. Biochem. 65 (2001) 21102112.

[9] D. Fiorini, S. Giuli, E. Marcantoni, L. Quassinti, M. Bramucci, C. Amantini, G. Santoni, F. Buonanno, C. Ortenzi, A straightforward diastereoselective synthesis and evaluation of climacostol, a natural product with anticancer activities, Synthesis 9 (2010) 1550-1556.

[10] M. Picardo, S. Passi, M. Nazzaro-Porro, A. Breathnach, C. Zompetta, A. Faggioni, P. Riley, Mechanism of antitumoral activity of catechols in culture, Biochem. Pharmacol. 36 (1987) 417-425.

[11] A. Kozubek, R. Zarnowski, M. Stasiuk, J. Gubernator, Natural amphiphilic phenols as bioactive compounds, Cell. Mol. Biol. Lett. 6 (2001) 351-355.

[12] P. Filip, T. Anke, O. Sterner, 5-(2'-oxoheptadecyl)-resorcinol and 5-(2'oxononadecyl)-resorcinol, cytotoxic metabolites from a wood-inhabiting basidiomycete, Z. Naturforsch. 57 (2002) 1004-1008.

[13] L. Barbini, P. Lopez, J. Ruffa, V. Martino, G. Ferraro, R. Campos, L. Cavallaio, Induction of apoptosis on human hepatocarcinoma cell lines by an alkyl resorcinol isolated from Lithraea molleoides, World J. Gastroenterol. 7 (2006) 5959-5963.

[14] D. Petrelli, F. Buonanno, L.A. Vitali, C. Ortenzi, Antimicrobial activity of the protozoan toxin climacostol and its derivatives, Biologia 67 (2012) 525-529.

[15] F. Buonanno, C. Ortenzi, The protozoan toxin climacostol and its derivatives: cytotoxicity studies on 10 species of free-living ciliates, Biologia 65 (2010) 675-680.

[16] Y. Muto, Y. Tanabe, K. Kawai, H. Iio, Inhibition of mitochondrial respiration by climacostol, Jpn. J. Protozool. 36 (2003) 25-26.

[17] Y. Muto, Y. Tanabe, K. Kawai, Y. Okano, H. Iio, Climacostol inhibits Tetrahymena motility and mitochondrial respiration, Cent. Eur J. Biol. 6 (2011) 99-104.

[18] F. Buonanno, L. Quassinti, M. Bramucci, C. Amantini, R. Lucciarini, G. Santoni, H. Ilo, C. Ortenzi, The protozoan toxin climacostol inhibits growth and induces apoptosis of human tumor cell lines, Chem. Biol. Interact. 176 (2008) 151-164.

[19] A. Kozubek, J.H.P. Tyman, Bioactive phenolic lipids, in: Atta-ur-Rahman (Ed.), Studies in natural products chemistry, Elsevier Science, Amsterdam, vol. 30, 2005, pp. 111-190.

[20] S.R. Starck, J.Z. Deng, S.M. Hecht, Naturally occurring alkylresorcinols that mediate DNA damage and inhibit its repair, Biochemistry 39 (2000) 24132419.
[21] O.K. Davydova, D.G. Deryabin, A.N. Nikiyan, G.I. El'Registan, Mechanisms of interaction between DNA and chemical analogues of microbial anabiosis autoinducers, Microbiology 5 (2005) 533-541.

[22] W. Lytollis, R.T. Scannell, H. An, V.S. Murty, K.S. Reddy, J.R. Barr, S.M. Hecht, 5alkylresorcinols from Hakea trifurcata that cleave DNA, J. Am. Chem. Soc. 117 (1995) 12683-12690.

[23] U.S. Singh, R.T. Scannell, H. An, B.J. Carter, S.M. Hecht, DNA cleavage by di and trihydroxyalkylbenzenes. Characterization of products and the role of 02 , Cu(II), and alkali, J. Am. Chem. Soc. 117 (1995) 12691-12699.

[24] J. Ma, S.H. Jones, S.M. Hecht, Phenolic acid amides: a new type of DNA strand scission agent from Piper caninum, Bioorg. Med. Chem. 12 (2004) 3885-3889.

[25] A. Russo, V. Cardile, A. De Ioannes, J. Garbarino, Effect of litreol on the viability of human cancer cells, Chem. Biol. Interact. 179 (2009) 178-184.

[26] Y. Jung, Y. Surh, Oxidative DNA damage and cytotoxicity induced by copperstimulated redox cycling of salsolinol, a neurotoxic tetrahydroisoquinoline alkaloid, Free Rad. Biol. Med. 30 (2001) 1407-1417.

[27] M. Ito, K. Murakami, M. Yoshino, Antioxidant action of eugenol compounds: role of metal ion in the inhibition of lipid peroxidation, Food Chem. Toxicol. 43 (2005) 461-466

[28] S. Oikawa, K. Hirosawa, S. Kawanishi, Site specificity and mechanism of oxidative DNA damage induced by carcinogenic catechol, Carcinogenesis 22 (2001) 1239-1245.

[29] R. Bera, B.K. Sahoo, K.S. Ghosh, S. Dasgupta, Studies on the interaction of isoxazolcurcumin with calf thymus DNA, Int. J. Biol. Macromol. 42 (2008) 14-21.

[30] R.F. Steiner, L. Weinryb, Excited States of Protein and Nucleic Acid, Plenum Press, New York, 1971.

[31] J.R. Lakowicz, Principles of Fluorescence Spectroscopy, third ed., Springer, New York, 2006.

[32] L.M. Sayre, K.Q. Ling, Y. Lee, D. Macikenas, J.D. Protasiewicz, Copper(II)mediated autoxidation of tert-butylresorcinols, J. Org. Chem. 68 (2003) 13581366.

[33] S. Bi, C. Qiao, D. Song, Y. Tian, D. Gao, Y. Sun, H. Zhang, Study of interactions of flavonoids with DNA using acridine orange as a fluorescence probe, Sens. Actuators, B 119 (2006) 199-208.

[34] S.M. Hecht, J. Ma, S.H. Jones, Phenolic acid amides: a new type of DNA strand scission agent from Piper caninum, Bioorg. Med. Chem. 12 (2004) 3885-3889.

[35] B. Giese, B. Kopping, T. Göbel, J. Dickhaut, G. Thoma, K.J. Kulicke, F. Trach, Radical cyclization reactions, Org. React. 48 (1996) 301-856.

[36] D.P. Curran, C.P. Jasperse, T.L. Fevig, Radical reactions in natural product synthesis, Chem. Rev. 43 (1991) 461-466.

[37] M. Stasiuk, A. Kozubek, Biological activity of phenolic lipids, Cell. Mol. Life Sci. 67 (2010) 841-860.

[38] S. Elmore, Apoptosis: A Review of Programmed Cell Death, Toxicol. Pathol. 35 (2007) 495-516.

[39] N. Dias, C. Bailly, Drugs targeting mitochondrial functions to control tumor cell growth, Biochem. Pharmacol. 70 (2005) 1-2.

[40] M.J. Burkitt, L. Milne, P. Nicotera, S. Orrenius, 1,10-Phenanthroline stimulates internucleosomal DNA fragmentation in isolated rat liver nuclei by promoting redox activity of endogenous copper ions, Biochem. J. 313 (1996) 163-169.

[41] S.M. Hadi, S.H. Bhat, A.S. Azmi, S. Hanif, U. Shamim, M.F. Ullah, Oxidative breakage of cellular DNA by plant polyphenols: A putative mechanism for anticancer properties, Semin. Cancer Biol. 17 (2007) 370-376.

[42] J. Cao, L. Jia, H.M. Zhou, Y. Liu, L.F. Zhong, Mitochondrial and nuclear DNA damage induced by curcumin in human hepatoma G2 cells, Toxicol. Sci. 91 (2006) 476-483.

[43] D. Wang, S.J. Lippard, Cellular processing of platinum anticancer drugs, Nat. Rev. Drug Discov. 4 (2005) 307-320.

[44] K. Cheung-Ong, G. Giaever, C. Nislow, DNA-damaging agents in cancer chemotherapy: serendipity and chemical biology, Chem. Biol. 20 (2013) 648-659. 